\title{
Exposure to cement dust at a Portland cement factory and the risk of cancer
}

\author{
Jørgen Vestbo, Kim M Knudsen, Edith Raffn, Bente Korsgaard, Finn Vejlø Rasmussen
}

\begin{abstract}
The relation between exposure to cement dust and cancer was examined in a population of 546 cement workers and a reference population of 858 randomly sampled men of similar age and area of residence. In 1974 all men gave lifelong occupational and smoking histories; information on incidence of cancer in the period 197485 was obtained from the Danish Cancer Registry. No increased risk of overall cancer was found among cement workers. Among men with more than 20 years exposure to cement dust, 14 cases of respiratory cancer were observed (observed/expected (O/E) 1.52, 95\% confidence interval (95\% CI) $0.90-2 \cdot 57)$ when compared with all Danish men. Men with 1-20 years exposure had O/E 1.14 (95\% CI 0.59-2.19) based on nine cases of cancer. After excluding all men with documented exposure to asbestos during employment in an asbestos cement factory no increased risk of overall cancer or respiratory cancer was found among cement workers compared with white collar workers from the local reference population, using a Cox regression model controlling for age and smoking habits. Relative risks were 0.5 (95\% CI $0 \cdot 1-1 \cdot 5)$ and $1.0(95 \%$ CI 0.4-2.6) for men with 120 and more than 20 years of exposure to cement dust respectively compared with white collar workers.
\end{abstract}

Medical Department $P$ and the Chest Clinic, Bispebjerg Hospital, Copenhagen and Clinic of Occupational Medicine, Rigshospitalet, Copenhagen J Vestbo

Statistical Research Unit, University of Copenhagen, Copenhagen

K M Knudsen

The Danish Cancer Society, Danish Cancer Registry, Institute of Cancer Epidemiology, Copenhagen

E Raffn

Occupational Health Service, Aalborg Portland

Cement, Aalborg

B Korsgaard

Medical Department B, Central County Hospital, Hillerød, Denmark

F V Rasmussen
Many articles concerning harmful effects on the respiratory tract of exposure to cement dust have been published. Most often obstructive airway disease has been the issue of investigation as described by Bazas. ${ }^{1}$ In the past few years, however, several studies have focussed on the possible carcinogenic effect of inhaled cement dust. Rafnsson and Johannesdottir found an increased number of deaths from lung cancer among masons exposed to cement dust, ${ }^{2}$ a finding not confirmed in a mortality study among cement plant workers, which found an excess mortality from stomach cancer among such workers, however. ${ }^{3}$ This finding was not reproduced in a later mortality study. ${ }^{4} \mathrm{~A}$ case-control study on laryngeal cancer found a significant risk ratio for workers in industries classified as concrete and cement manufacture. ${ }^{5}$ Chromium compounds, especially hexavalent chromium, have been suspected of being the carcinogenic agents, but the carcinogenic effect of inhaled cement dust must still be regarded as dubious. ${ }^{6}$

The aim of this study was to examine mortality from all cancers, respiratory cancer, and stomach cancer in a cohort of 1404 middle aged men examined in 1974 with reference to the risk of obstructive airways disease in men exposed to cement dust.

\section{Materials and methods}

STUDY POPULATION

The cohort under study was sampled in 1973 from the population of the city of Aalborg; it consisted of 1404 men aged $46-69$. The sample was (1) a $100 \%$ sample of men who had at some time before 1974 worked for one year or more in a particular Portland cement factory (546 men), and (2) a $6.6 \%$ sample of the remainder of the male population comprising men born on the first or fifteenth of each month (858 men). The main purpose of the study was to examine the effects of inhaled cement dust on ventilatory lung function and details of the study have been published earlier. ${ }^{7}$ Eighty nine per cent of the invited population participated in the cross sectional study.

All subjects were examined with lung function tests and interviews including the British Medical Research Council questionnaire, ${ }^{8}$ questions on 
lifelong smoking history, and full occupational and residential history.

\section{CEMENT WORKERS}

In 1974 cement workers gave information on number of years of employment in the Portland cement factory. This information was compared with that of the cement factory's personnel files to enumerate number of years in jobs with significant exposure to cement dust. Exposure to cement dust during employment was considerable. No regular dust measurements were conducted before 1974. Personal dust sampling during the first half of 1974 , however, showed $9 \%$ of respirable dust measurements above $5 \mathrm{mg} / \mathrm{m}^{3}$. Also, no exact registration of occupation within the cement plant before 1974 could be used for more precise estimation of exposure. Since 1975 the concentrations of soluble hexavalent chromium have been measured and in 1975 mean concentration in 10 samples was $9.8 \mathrm{mg} \mathrm{Cr}^{6+} / \mathrm{kg}$. Since 1981 all cements have been chromate reduced resulting in mean contents of hexavalent chromium lower than $2 \mathrm{mg}$ $\mathrm{Cr}^{6+} / \mathrm{kg}$.

No information on age at first employment or number of employments was registered in 1974. A total of 62 men had been employed at other cement factories for 1-36 years, median six years. No information on exposure to cement dust during these years is available.

\section{REFERENT POPULATION}

Each occupational employment was classified into one of three occupational categories: "blue collar workers," with exposure to dust, or temperature variability, or physical exertion, or a combination of these exceeding those of an average shop assistant in Aalborg; "white collar workers," with the above mentioned exposures equivalent to or lower than those of an average shop assistant; and "farming." A main occupational category was thereafter defined, for subjects from the referent population, as the occupational category in which they had spent at least half of their working life. Working life was defined as the time from age 18 to the time of the interview or age 65 , whichever came first. A total of 544 men had blue collar work, 193 men had white collar work, and 49 men had farming as their main occupational category; 71 subjects could not be classified as to main occupational category.

A total of 66 men from the referent population had been employed at other cement factories for 1-34 years, median 11 years. Of these, 54 men had blue collar work as their main occupational category, one man was classified as a white collar worker, six were from rural occupations, and five could not be classified in any main occupational category.

\section{INFORMATION ON POSSIBLE CONFOUNDERS}

Thorough interviews on lifelong smoking habits were carried out by one physician. Pack-years of cigarettes were considered the most relevant smoking parameter. The only Danish asbestos cement industry, Danish Eternit-Fabrik (DEF), is located close to the cement factory in Aalborg. In 1974 specific information on employment at DEF was not registered. In 1988 information on whether subjects had been employed at DEF was obtained from a subregister under the Danish Cancer Registry. This registry was used for examining cancer and mortality among DEF employees. Information on previous employment at DEF (yes or no) was available for this study. Number of years in urban residence until 1974 was enumerated for each subject. For the purpose of controlling for urbanisation, a dichotomous variable was constructed. It was coded 1 for subjects who had lived at least two thirds of their lives in urban dwellings, otherwise 0 .

\section{REGISTRATION OF CANCER AND DEATH}

Information on all incident cancer cases from the time of examination in 1974 to 15 June 1985 was obtained from the Danish Cancer Registry. Cases of cancer were coded according to a modified version of International Classification of Diseases, seventh rev- 8 ision (ICD-7).$^{10}$ Information on deaths in the period from examination in 1974 to 15 June 1985 wase obtained from the Danish National Board of Health.

\section{CALCULATIONS AND STATISTICAL ANALYSIS}

For each subject person-years at risk were counted from examination in 1974 until date of registration of cancer within the site of cancer under study, date of death, or 15 June 1985. Expected numbers of cancer cases (E) were calculated based on cause specific cancer incidence rates for five year age groups and five year calendar periods for the total male Danish population.

Because information on the date of diagnosis was available, it was possible to apply the multivariate Cox regression model ${ }^{11}$ for survival data, which takes into account the exact time of death or in this case diagnosis of cancer.

The model assumes that the covariates $z_{1} \ldots z_{k}$ have a multiplicative effect on cancer. The formulation of the model is:

$$
\lambda(a, z)=\lambda_{0}(a) \exp \left(\beta_{1} z_{1}+\ldots+\beta_{k} z_{k}\right)
$$

where $\lambda(a, z)$ is the force of cancer at age a for men with covariates $z_{i} \ldots z_{k} ; \beta_{i} \ldots \beta_{k}$ are unknown regression coefficients to be estimated; and $\lambda_{0}$ (a) represents the age specific baseline cancer risk-that is, the cancer risk for a man of age a for whom $z_{\mathrm{i}}=\ldots=\mathrm{z}_{\mathrm{k}}=0$.

The men were evaluated from age at the clinical examination until age at cancer diagnosis, age at 
Table 1 Age, description of smoking histories, and information on exposure to asbestos at DEF

\begin{tabular}{|c|c|c|c|c|c|}
\hline & \multirow{2}{*}{\multicolumn{2}{|c|}{$\frac{\text { Cement workers }}{\text { Duration of exposure }}$}} & \multicolumn{3}{|c|}{ Random population sample } \\
\hline & & & \multirow{2}{*}{$\begin{array}{l}\text { Blue } \\
\text { collar } \\
\text { workers }\end{array}$} & \multirow{2}{*}{$\begin{array}{l}\text { White } \\
\text { collar } \\
\text { workers }\end{array}$} & \multirow[b]{2}{*}{ Others } \\
\hline & $1-20 y$ & $\geqslant 21 y$ & & & \\
\hline $\begin{array}{l}\text { No of men } \\
\text { Mean age (y) } \\
\text { Never smokers (\%) } \\
\text { Heavy smokers defined as > }>20 \text { pack-years of cigarettes (\%) } \\
\text { Exposed to asbestos }(\%) \text { (at DEF) }\end{array}$ & $\begin{array}{c}274 \\
55 \cdot 5 \\
4 \\
18 \\
22\end{array}$ & $\begin{array}{c}272 \\
57 \cdot 7 \\
7 \\
18 \\
5\end{array}$ & $\begin{array}{c}544 \\
55 \cdot 9 \\
9 \\
18 \\
12\end{array}$ & $\begin{array}{l}193 \\
55 \cdot 9 \\
10 \\
19 \\
2\end{array}$ & $\begin{array}{l}121 \\
56 \cdot 6 \\
15 \\
15 \\
10\end{array}$ \\
\hline
\end{tabular}

death, or 15 June 1985. The age of the men at the time of examination varied from 46 to 69 so estimation in the model must deal with left truncation or "delayed entry." Because age is beyond doubt a predictor of cancer for men older than 50 , age is used here as the basic underlying time scale in the Cox regression model. Therefore, age cannot be included as a covariate and its effect cannot be examined for significance. Our analysis can only describe risk of cancer at age greater than 51 . Effects are expressed as relative risks (RRs), given as exp $(\hat{\beta})$ in our model together with $95 \%$ confidence intervals $(95 \% \mathrm{CIs})$.

\section{Results}

Table 1 shows mean age and a crude description of smoking histories and exposure to asbestos at DEF for two subgroups of cement workers (with 20 years of exposure to cement dust as dividing point) and three subgroups of the random population sample. Concerning mean age, the five groups were comparable but minor differences in smoking histories were found. Men in rural occupations and men who could not be classified in a main occupational category ("others" in table 1) had smoked less than the other subgroups.

A total of 15 men had cancer diagnosed before examination in 1974; they were evenly distributed between occupational subgroups and were excluded from further analyses. Table 2 shows the observed (O) and expected numbers of incident cases of cancer in the period $1974-85$ for all cancers, respiratory cancer (ICD-7, 161-164), including cancer of the larynx and trachea, and stomach cancer (ICD-7, 151). A total of 162 cancers were observed $v 158.0$ expected (O/E 1.03, 95\% CI 0.88-1.20). For respiratory cancer, 58 cancers were observed $v 41 \cdot 3$ expected (O/E 1.41, 95\% CI 1.09-1.82). For stomach cancer, five cancers were observed $v 6.6$ expected (O/E 0.76, 95\% CI 0.32-1.83). Concerning respiratory cancer, both groups of cement workers had $\mathrm{O} /$ Es greater than 1.00; for subjects with more than 21 years of exposure to cement dust the $\mathrm{O} / \mathrm{E}$ was $1.52(95 \%$ CI 0.90-2.57). Blue collar workers from the random population sample had $\mathrm{O} / \mathrm{E}$ significantly greater than $1 \cdot 00(1 \cdot 63,95 \%$ CI $1 \cdot 10-2 \cdot 41)$. Included in respiratory cancer were five cases of cancer of the larynx; 3.46 were expected. The five cases were evenly distributed between subgroups.

One case of mesothelioma was found $v 0.85$ expected in the cohort. The case was a cement worker with 28 years of exposure to cement dust and no exposure to asbestos at DEF.

A total of 154 men had been exposed to asbestos at DEF. In this subgroup 24 cases of cancer were observed $v 15.4$ expected (O/E $1.56,95 \%$ CI $1.05-$

Table 2 No of observed $(O)$ and expected $(E)$ cases of cancer and $O / E$ ratio within each category of cancer

\begin{tabular}{|c|c|c|c|c|c|}
\hline & \multicolumn{2}{|c|}{ Cement workers } & \multicolumn{3}{|c|}{ Random population sample } \\
\hline & \multicolumn{2}{|c|}{ Duration of exposure } & \multirow{2}{*}{$\begin{array}{l}\text { Blue } \\
\text { collar } \\
\text { workers }\end{array}$} & \multirow{2}{*}{$\begin{array}{l}\text { White } \\
\text { collar } \\
\text { workers }\end{array}$} & \multirow[b]{2}{*}{ Others } \\
\hline & $1-20 y$ & $\geqslant 21 y$ & & & \\
\hline \multicolumn{6}{|l|}{ All sites: } \\
\hline $\begin{array}{l}\text { Observed (O) } \\
\text { Expected (E) } \\
\text { O/E }(95 \% \text { CI) }\end{array}$ & $\begin{array}{l}22 \\
30 \cdot 8 \\
0 \cdot 71 \\
(0 \cdot 47-1 \cdot 08)\end{array}$ & $\begin{array}{l}36 \\
34 \cdot 6 \\
1 \cdot 04 \\
(0 \cdot 75-1 \cdot 44)\end{array}$ & $\begin{array}{l}69 \\
58 \cdot 8 \\
1 \cdot 17 \\
(0 \cdot 92-1 \cdot 48)\end{array}$ & $\begin{array}{l}26 \\
21 \cdot 3 \\
1 \cdot 22 \\
(0 \cdot 83-1 \cdot 79)\end{array}$ & $\begin{array}{l}9 \\
12 \cdot 6 \\
0 \cdot 71 \\
(0 \cdot 37-1 \cdot 36)\end{array}$ \\
\hline $\begin{array}{l}\text { Respiratory cancer: } \\
\text { Observed (O) } \\
\text { Expected (E) } \\
\text { O/E }(95 \% \text { CI })\end{array}$ & $\begin{array}{l}9 \\
7 \cdot 9 \\
1 \cdot 14 \\
(0 \cdot 59-2 \cdot 19)\end{array}$ & $\begin{array}{l}14 \\
9 \cdot 2 \\
1.52 \\
(0 \cdot 90-2 \cdot 57)\end{array}$ & $\begin{array}{l}25 \\
15 \cdot 3 \\
1 \cdot 63 \\
(1 \cdot 10-2 \cdot 41)\end{array}$ & $\begin{array}{l}7 \\
5 \cdot 6 \\
1 \cdot 24 \\
(0 \cdot 59-2 \cdot 60)\end{array}$ & $\begin{array}{l}3 \\
3 \cdot 2 \\
0.95 \\
(0.31-2.93)\end{array}$ \\
\hline $\begin{array}{l}\text { Stomach cancer: } \\
\text { Observed (O) } \\
\text { Expected (E) } \\
\text { O/E }(95 \% \text { CI })\end{array}$ & $\begin{array}{l}1 \\
1 \cdot 3 \\
0 \cdot 77 \\
(0 \cdot 11-5 \cdot 68)\end{array}$ & $\begin{array}{l}0 \\
1.5 \\
-\end{array}$ & $\begin{array}{l}3 \\
2 \cdot 4 \\
1 \cdot 25 \\
(0 \cdot 40-3 \cdot 81)\end{array}$ & $\begin{array}{l}1 \\
0 \cdot 9 \\
1 \cdot 11 \\
(0 \cdot 16-8 \cdot 09)\end{array}$ & $\begin{array}{l}0 \\
0.5 \\
-\end{array}$ \\
\hline
\end{tabular}


2.33); nine of these were cases of respiratory cancer $v$ $4 \cdot 0$ expected $(\mathrm{O} / \mathrm{E} 2 \cdot 25,95 \%$ CI $1 \cdot 17-4 \cdot 32)$. No cases of stomach cancer were observed $v 0.61$ expected. The location of the remaining 15 cases did not differ from that expected.

To meet the assumptions for the Cox model, especially the criteria of proportional mortality in occupational subgroups, the cohort was further restricted to $1128 \mathrm{men}$. Men with exposure to asbestos at DEF were excluded. Furthermore, men from the random population sample with either farming as main occupational category or no main occupational category constituted a heterogeneous subgroup and they were excluded. Of the 1128 men, 130 had cancer diagnosed and 45 had respiratory cancer. As an interaction between age and smoking on cancer morbidity was found, the Cox regression model was modified so that each of the effects of the two degrees of smoking compared with non-smoking was divided into three age specific effects measuring the increased morbidity in age intervals of younger than $60,60-70$, and older than 71 . Smoking habits expressed as packyears of cigarettes were not only strongly associated with respiratory cancer, but the impact with age was accelerative with RRs increasing from 1.4 for men younger than 60 who had smoked 1-20 pack-years to 8.4 for men over 70 with a smoking record of more than 20 pack-years, compared with men who had smoked less than one pack-year. The same trend was also found, although to a lesser extent, in the analyses of all cancers. No effect of urbanisation, entered as a dichotomous variable, was found. Due to the limited number of cases of respiratory cancer it was not possible to examine the effect of cement dust in the Cox model stratified on age. Instead we used an unstratified Cox model with smoking entered as two covariates-that is, 1-20 pack-years of cigarettes and 21 or more pack-years, both by contrast with less than 1 pack-year. Table 3 gives the results of this final Cox model on respiratory cancer. Neither of the two cement worker subgroups had RRs higher than 1.00 when compared with white collar workers.

Table 3 Results of the final Cox regression model with respiratory cancer as outcome using age as the underlying time scale and including smoking and occupational categories as covariates

\begin{tabular}{|c|c|}
\hline Variable & $R R(95 \% C I)$ \\
\hline $\begin{array}{l}\text { Light smokers }(1-20 \text { pack-years })^{\star} \\
\text { Heavy smokers }(\geqslant 21 \text { pack-years })^{\star}\end{array}$ & $\begin{array}{l}2 \cdot 7(1 \cdot 3-6 \cdot 0) \\
3 \cdot 6(1 \cdot 5-8 \cdot 4)\end{array}$ \\
\hline $\begin{array}{l}\text { Cement workers: } \dagger \\
1-20 \text { years of exposure } \\
\geqslant 21 \text { years of exposure }\end{array}$ & $\begin{array}{l}0.5(0 \cdot 1-1 \cdot 5) \\
1 \cdot 0(0 \cdot 4-2 \cdot 6)\end{array}$ \\
\hline Blue collar workers $\dagger$ & $1.3(0.5-3.0)$ \\
\hline
\end{tabular}

$\mathbf{R R}=$ relative $\operatorname{risk}(\exp (\hat{\beta}))$.

$\star$ By contrast with men having smoked less than one pack-year.

†By contrast with white collar workers.

\section{Discussion}

Inhaled cement dust is suspected of being able to cause cancer of the lungs ${ }^{2}$ and the stomach. ${ }^{3}$ As pointed out by Doll ${ }^{\mathrm{i} 2}$ interpretation of solitary epidemiological studies showing an excess risk of cancer due to occupational exposure is not without problems. In the case of cement dust and cancer, scientifically satisfactory studies have been published that have been unable to confirm the increased risk of lung cancer ${ }^{3}$ and stomach cancer. ${ }^{4}$

In our study no increased risk of cancer was found among cement workers when compared with a suitable referent population. Instead, our study confirmed the effects of well known risk factors for cancer, in particular cancer in the lung and airways-namely, the effects of age, smoking, and exposure to asbestos. Table 2 shows that most $\mathrm{O} /$ Es were greater than $1 \cdot 00$. This was most obvious for blue collar workers from the referent population and most likely reflects the inadequacy of the total male population as a referent population in a study of occupational cancer. This is due both to the lack of controlling for smoking when using the total population and to the heterogeneity of this reference population. Furthermore, the effect of exposure to asbestos presumably raises the $\mathrm{O} / \mathrm{E}$ ratio in cement workers and other blue collar workers.

No increased risk of either cancer of the larynx ob stomach cancer was found among cement workers Few of these cancers were found in the cohort and this tends to make conclusions on the effect of cement on these cancers weaker. Nevertheless, our findings accord with those of Amandus ${ }^{4}$ regarding stomach cancer; among all cement workers in our study $\mathrm{O} / \mathrm{E}$ was $0 \cdot 4$.

An increased risk of lung cancer has only been reported in the Icelandic study on mortality among masons ${ }^{2}$; their finding was based on nine deaths and smoking was only controlled for indirectly. In that study it is not self evident why cement dust, and especially hexavalent chromium in cement dust, was regarded as the most probable carcinogenic agent. Possibly the assumption was based on the wellknown carcinogenic effect of chromate in other industries. ${ }^{13}$ The concentration of chromate in cement is, however, very low and lower than that found in industries where an excess risk of cancer has been shown. It thus seems unlikely that chromate in cement dust could be responsible for a measurable increased risk of cancer. Furthermore, as well as the present study and the mortality study by $\mathrm{McDowall},{ }^{3}$ a Danish record linkage study found no increased mortality from all cancers and lung cancer, with standardised mortality ratios of 87 and 98 based on 118 and 47 deaths respectively among cement workers. ${ }^{14}$

In our study all cement workers had been exposed to cement dust. Furthermore, the detailed information from 1974 on smoking habits and the use of a 
random population sample from the same geographical area strengthen the validity of our findings. Our study also has drawbacks. Firstly, the degree of exposure was expressed as duration of employment only and although exposure to cement dust was considerable during employment, no detailed information is available. Secondly, due to the way data were recorded in 1974, information on latency period is not available. Thirdly, the two large occupational categories in the random population sample-blue collar workers and white collar workers-are not homogeneous reference groups. Blue collar workers have various exposures and many have undoubtedly been exposed to asbestos at a large shipyard in Aalborg. Also, white collar workers may differ from the general concept of what these are as they do not simply represent office staff. Finally, the power of the study varies according to site of the cancer under study and the size of the occupational subgroup. For cement workers, the probability of obtaining an $\mathrm{O} / \mathrm{E}$ of 2 (hypothesised true value) significant at the 0.05 level (one sided) for respiratory cancer is $73 \%$ and $79 \%$ in the two cement worker subgroups. ${ }^{15}$ Considered jointly, the power for all cement workers ( 546 men) regarding respiratory cancer would be $95 \%$. For stomach cancer, a hypothesised true $\mathrm{O} / \mathrm{E}$ of 2 in the two cement worker subgroups would only be obtained with a probability of $14 \%$ and $18 \%$; in all cement workers the probability would be $37 \%$.

Despite these shortcomings, we consider our results sufficiently valid for conclusion regarding the carcinogenic risk of exposure to cement dust. Thus our study casts serious doubt on previous studies showing an excess risk of cancer, especially respiratory cancer, among cement workers.

This study was supported by grants from The Danish National Association against Lung Diseases.
Requests for reprints to: Jørgen Vestbo, Department of Haematology C, Gentofte Hospital, Niels Andersensvej 65, DK-2900 Hellerup, Denmark.

1 Bazas T. Effects of Occupational exposure to dust on the respiratory system of cement workers. J Soc Occup Med 1980;30:31-6.

2 Rafnsson V, Johannesdottir SG. Mortality among masons in Iceland. Br J Ind Med 1986;43:522-5.

$3 \mathrm{McDowall} \mathrm{ME}$. A mortality study of cement workers. $\mathrm{Br} \mathrm{J}$ Ind Med 1984;41:179-82.

4 Amandus HE. Mortality from stomach cancer in United States cement plant and quarry workers, 1950-80. Br J Ind Med 1986;43:526-8.

5 Olsen J, Sabroe S. Occupational causes of laryngeal cancer. $J$ Epidemiol Community Health 1984;38:117-21.

$6 \mathrm{McDowall} \mathrm{M}$. Cement workers and cancer: epidemiology at work? Br J Ind Med 1986;43:505-6.

7 Rasmussen FV, Borchsenius L, Holstein B, Sølvsteen P. Lung function and long-term exposure to cement dust. Scand $J$ Respir Dis 1977;58:252-64.

8 Medical Research Council's committee on the aetiology of chronic bronchitis. Standardized questionnaires on respiratory symptoms. $B M J 1960 ; 2: 1665$.

9 Raffn E, Lynge E, Juel K, Korsgaard B. Incidence of cancer and mortality among employees in the asbestos cement in industry in Denmark. Br J Ind Med 1989;46:90-6.

10 Clemmesen J. Statistical studies in the aetiology of malignant neoplasms. I. Review and results. Acta Pathol Microbiol Scand 1977;(suppl 261).

11 Cox DR, Oakes D. Analysis of survival data. London: Chapman and Hall, 1984.

12 Doll R. Occupational cancer: a hazard for epidemiologists. Int $J$ Epidemiol 1985;14:22-31.

13 International Agency for Research on Cancer. Monographs, suppl 7. On the evaluation of the carcinogenic risk to humans. Lyon: IARC, 1987.

14 Andersen O. Dodelighed og erhverv 1970-80. Copenhagen: Danmarks Statistik, 1985.

15 Breslow NE, Day NE. Statistical methods in cancer research. Volume 2. The design and analysis of cohort studies. Lyon: International Agency for Research on Cancer, 1987.

Accepted 15 April 1991 